\title{
Stressed and strained state of layered cylindrical shell under local convective heating
}

\author{
Musii R. S., Zhydyk U. V., Turchyn Ya. B., Svidrak I. H., Baibakova I. M. \\ Lviv Polytechnic National University, \\ 12 S. Bandera Str., 79013, Lviv, Ukraine
}

(Received 3 November 2021; Revised 21 January 2022; Accepted 23 January 2022)

\begin{abstract}
The stress-strain state of a layered composite cylindrical shell under local heating by the environment due to convective heat exchange has been studied. The equation of the six-modal theory of thermoelasticity and the two-dimensional equation of thermal conductivity of inhomogeneous anisotropic shells are used for this purpose. The solution of the nonstationary heat transfer problem and the quasi-static thermoelasticity problem for a finite hinged orthogonally reinforced shell of symmetric structure is found by the methods of integral Fourier and Laplace transforms. Numerical results are given for the three-layer shell.
\end{abstract}

Keywords: thermoelasticity, layered materials, temperature loading, cylindrical shell.

2010 MSC: $74 \mathrm{~K} 25$

DOI: $10.23939 / \mathrm{mmc} 2022.01 .143$

\section{Introduction}

In the literature [1], there are studies of the thermal stressed state of an isotropic cylindrical shell made of a functional-gradient material under local thermal heating. The temperature regime of the dental crown, which is modeled by a cylindrical shell made of isotropic functional-gradient cermets, was also studied in [2]. In addition, layered cylindrical shells are widely used in many branches of modern technology, in particular in aerospace construction, to increase the strength and rigidity of structures, as well as to protect them from low or high temperatures. Therefore, an important engineering task is to build mathematical models and conduct research on layered structures to analyze their performance [3-6]. Temperature fields and stresses in layered structures were studied both on the basis of three-dimensional equations [7,8] and two-dimensional ones [9-11]. Analytical [12]]and numerical [13] methods were used to construct the solutions. The relationship between temperature and mechanical fields was analyzed in [14]. Thermoelectromechanical analysis was performed in [15] for multilayer piezoelectric shells. The thermomechanical stability of layered structures was investigated [16]. More literature on layered composite structures can be found in $[3,4]$.

The aim of this paper is to investigate the stress-strain state of an orthotropic layered cylindrical shell of regular symmetrical structure under the local heating due to convective heat exchange with the environment on the basis of two-dimensional equations of heat transfer and equations of thermoelasticity of the six-modal theory of shells.

\section{Problem formulation and basic governing equations}

Consider a circular cylindrical shell with a radius of the middle surface $R$, length $l$ and constant thickness $2 h$, composed of perfectly bonded orthotropic layers of the same thickness of the same thickness, which are located symmetrically with respect to the middle surface. The axes of orthotropy of each layer are alternately oriented at an angle $0^{\circ}$ or $90^{\circ}$ to the axis of the shell. The number of layers with orientation $0^{\circ}$ is equal to $n_{1}$, and of ones with orientation $90^{\circ}$ is $n_{2}$. The total number of layers $n=n_{1}+n_{2}$ is odd. The shell is attributed to the orthogonal coordinate system $x, \theta, z$ of the axial, circumferential, and radial coordinates, respectively. The origin is placed in the middle surface of the layer with orientation $0^{\circ}$. 
Assume that at the initial moment of time $\tau=0$, the outer surface $z=+h$ of the shell has the same temperature as the environment. From the moment of time $\tau>0$, it is heated by the environment whose temperature changes according to the law

$$
t_{c}^{+}(x, \theta, \tau)=t^{*} t_{c}(x, \theta) t(\tau),
$$

where $t^{*}=$ const, functions $t_{c}(x, \theta)$ and $t(\tau)$ reflect the dependence of the environment temperature on coordinates and time, respectively.

The inner surface $z=-h$ is surrounded with the environment at zero-temperature $t_{c}^{-}=0$. Convective heat exchange with heat transfer coefficient $\alpha_{z}$ takes place between the environment and surfaces $z= \pm h$.

The temperature field and the stress-strain state of such a shell are investigated on the basis of a mathematical model of inhomogeneous anisotropic shells [5].

Then to determine the temperature field $t(x, \theta, z, \tau)$, we formulate the nonstationary equations of heat conduction in the form as follows:

$$
\begin{aligned}
& \Delta_{(1)} T_{1}+\Lambda_{3}^{(1)} /(R h) T_{2}-2 \alpha_{z} T_{1}-2 h c_{\varepsilon} \partial_{\tau} T_{1}=-t^{*} t_{c}(x, \theta) t(\tau) \alpha_{z} \\
& \Delta_{(3)} T_{2}-\Lambda_{3}^{(1)} / h^{2} T_{2}-2 \alpha_{z} T_{2}-2 / 3 h c_{\varepsilon} \partial_{\tau} T_{2}=-t^{*} t_{c}(x, \theta) t(\tau) \alpha_{z} .
\end{aligned}
$$

Here,

$$
\begin{gathered}
\Delta_{(k)}=\Lambda_{1}^{(k)} \partial_{11}^{2}+\Lambda_{2}^{(k)} \partial_{22}^{2} ; \quad(k=1,3) ; \quad t=T_{1}+\frac{z}{h} T_{2} ; \quad T_{i}=\frac{2 n-1}{2 h^{i}} \int_{-h}^{h} t z^{i-1} d z ; \quad(i=1,2) \\
\left\{\Lambda_{1}^{(1)}, \Lambda_{2}^{(1)}\right\}=\left[\left\{\lambda_{1}, \lambda_{2}\right\} n_{1}+\left\{\lambda_{2}, \lambda_{1}\right\} n_{2}\right] \frac{2 h}{n} ; \quad \Lambda_{3}^{(1)}=2 h \lambda_{3} ; \\
\left\{\Lambda_{1}^{(3)}, \Lambda_{2}^{(3)}\right\}=\frac{2 h}{3}\left[\begin{array}{c}
\left.\left\{\lambda_{1}, \lambda_{2}\right\}\left(1-\frac{n^{3}-3 n^{2}+2}{2 n^{3}}\right)+\left\{\lambda_{2}, \lambda_{1}\right\}\left(\frac{n^{3}-3 n^{2}+2}{2 n^{3}}\right)\right] \\
\partial_{1}=\partial / \partial x ; \quad \partial_{2}=\partial / \partial \theta ; \quad \partial_{\tau}=\partial / \partial \tau ;
\end{array}\right.
\end{gathered}
$$

$\lambda_{j}$ is the coefficients of heat conductivity of an orthotropic body; $c_{\varepsilon}$ is the specific volumetric heat capacity.

To determine the stress-strain state of the shell, we employ the equilibrium equation in terms of generalized displacements $u, v, w, \gamma_{1}, \gamma_{2}, \gamma_{3}$ :

$$
L_{i 1} u+L_{i 2} v+L_{i 3} w+L_{i 4} \gamma_{1}+L_{i 5} \gamma_{2}+L_{i 6} \gamma_{3}=b_{i}, \quad(i=1,2, \ldots, 6),
$$

where the differential operators $L_{i j}\left(L_{i j}=L_{j i}\right)$ and free terms $b_{i}$ of the system have the form:

$$
\begin{gathered}
L_{11}=A_{11} \partial_{11}^{2}+A_{66} / R^{2} \partial_{22}^{2}, \quad L_{12}=\left(A_{12}+A_{66}\right) / R \partial_{12}^{2}, \\
L_{13}=A_{12} / R \partial_{1}, \quad L_{14}=0, \quad L_{15}=0, \quad L_{16}=A_{13} \partial_{1}, \\
L_{22}=A_{66} \partial_{11}^{2}+A_{22} / R^{2} \partial_{22}^{2}-k^{\prime} A_{44} / R^{2}, \\
L_{23}=\left(A_{22}+k^{\prime} A_{55}\right) / R^{2} \partial_{2}, \quad L_{24}=0, \quad L_{25}=k^{\prime} A_{55} / R, \quad L_{26}=A_{23} / R \partial_{2}, \\
L_{33}=-k^{\prime} A_{44} \partial_{11}^{2}+\left(A_{22}-k^{\prime} A_{55} \partial_{22}^{2}\right) / R^{2}, \quad L_{34}=-k^{\prime} A_{44} \partial_{1}, \quad L_{35}=-k^{\prime} A_{55} / R \partial_{2}, \quad L_{36}=A_{23} / R, \\
L_{44}=D_{11} \partial_{11}^{2}+D_{66} / R^{2} \partial_{22}^{2}-k^{\prime} A_{44}, \quad L_{45}=\left(D_{12}+D_{66}\right) / R \partial_{12}^{2}, \\
L_{46}=D_{12} / R \partial_{1}, \quad L_{55}=D_{66} \partial_{11}^{2}+D_{22} / R^{2} \partial_{22}^{2}-k^{\prime} A_{55}, \\
L_{56}=D_{22} / R^{2} \partial_{2}, \quad L_{66}=-k^{\prime} D_{44} \partial_{11}^{2}-k^{\prime} D_{55} / R^{2} \partial_{22}^{2}+A_{33}+D_{22} / R^{2}, \\
b_{1}=A_{11}^{t} \partial_{1} T_{1}, \quad b_{2}=A_{22}^{t} / R \partial_{2} T_{1}, \quad b_{3}=A_{22}^{t} / R T_{1}, \\
b_{4}=D_{11}^{t} / h \partial_{1} T_{2}, \quad b_{5}=D_{22}^{t} /(R h) \partial_{2} T_{2}, \quad b_{6}=A_{33}^{t} T_{1}+D_{22}^{t} /(R h) T_{2} .
\end{gathered}
$$

Here, the stiffness coefficients $A_{i j}, D_{i j}$ and $A_{i i}^{t}, D_{i i}^{t}$ were calculated by formulas for an odd number of layers that are symmetrically arranged with respect to the middle surface of the shell. 


$$
\begin{gathered}
\left\{A_{11}, A_{22}\right\}=\left[\left\{c_{11}, c_{22}\right\} n_{1}+\left\{c_{22}, c_{11}\right\} n_{2}\right] \frac{2 h}{n} ; \quad\left\{A_{12}, A_{33}, A_{66}\right\}=2 h\left\{c_{12}, c_{33}, c_{66}\right\} \\
\left\{A_{13}, A_{23}, A_{44}, A_{55}\right\}=\left[\left\{c_{13}, c_{23}, c_{44}, c_{55}\right\} n_{1}+\left\{c_{23}, c_{13}, c_{55}, c_{44}\right\} n_{2}\right] \frac{2 h}{n} \\
\left\{D_{11}, D_{22}\right\}=\frac{2 h^{3}}{3}\left[\left\{c_{11}, c_{22}\right\}\left(1-\frac{n^{3}-3 n^{2}+2}{2 n^{3}}\right)+\left\{c_{22}, c_{11}\right\} \frac{n^{3}-3 n^{2}+2}{2 n^{3}}\right] \\
\left\{D_{12}, D_{66}\right\}=\frac{2 h^{3}}{3}\left\{c_{12}, c_{66}\right\} ; \\
\left\{D_{44}, D_{55}\right\}=\frac{2 h^{3}}{3}\left[\left\{c_{44}, c_{55}\right\}\left(1-\frac{n^{3}-3 n^{2}+2}{2 n^{3}}\right)+\left\{c_{55}, c_{44}\right\} \frac{n^{3}-3 n^{2}+2}{2 n^{3}}\right] \\
\left\{A_{11}^{t}, A_{22}^{t}\right\}=\left[\left\{\beta_{1}^{t}, \beta_{2}^{t}\right\} n_{1}+\left\{\beta_{2}^{t}, \beta_{1}^{t}\right\} n_{2}\right] \frac{2 h}{n} ; \quad A_{33}^{t}=2 h \beta_{3}^{t} ; \\
\left\{D_{11}^{t}, D_{22}^{t}\right\}=\frac{2 h^{3}}{3}\left[\left\{\beta_{1}^{t}, \beta_{2}^{t}\right\}\left(1-\frac{n^{3}-3 n^{2}+2}{2 n^{3}}\right)+\left\{\beta_{2}^{t}, \beta_{1}^{t}\right\} \frac{n^{3}-3 n^{2}+2}{2 n^{3}}\right]
\end{gathered}
$$

where $c_{i j}$ are the coefficients of elasticity of the orthotropic body [1]; $\beta_{i}^{t}=c_{i j} \alpha_{j}^{t}$ is the coefficients of thermoelasticity; $\alpha_{j}^{t}$ is the coefficients of linear thermal expansion; $k^{\prime}$ stands for the shear coefficient [17].

\section{Problem solving method}

For the unambiguity of the solution of systems of equations of heat conduction (1) and thermoelasticity (2), we impose the boundary conditions for the key functions on edges $x=0$ and $x=l$ of the shell in the form:

$$
\begin{gathered}
T_{1}=T_{2}=0, \\
w=v=0 ; \quad \gamma_{3}=\gamma_{2}=0 ; \quad N_{1}=M_{1}=0 .
\end{gathered}
$$

The corresponding initial conditions at the initial moment of time $\tau=0$ are as follows:

$$
T_{1}(x, \theta, 0)=0, \quad T_{2}(x, \theta, 0)=0 .
$$

The system of heat conduction equations (1) for integral characteristics $T_{1}$ and $T_{2}$ of temperatures is solved by the methods of Laplace integral transform by time $\tau$ under initial conditions (5) and finite double Fourier transform by coordinates $x, \theta$ under boundary conditions (3). Then the solutions of the system of equations (1) can be given as

$$
\begin{aligned}
& T_{1}=\frac{t^{*} \mathrm{Bi}}{2} \sum_{n=1}^{\infty} \sum_{m=0}^{\infty} Q_{m n} \sum_{i \neq j}^{2} \frac{\left(p_{i}-G_{4}+3 G_{2}\right) Z_{i}\left(\tau^{\prime}\right)}{p_{i}-p_{j}} \sin \frac{\pi n x}{l} \cos m \theta \\
& T_{2}=\frac{t^{*} \mathrm{Bi}}{2} \sum_{n=1}^{\infty} \sum_{m=0}^{\infty} Q_{m n} \sum_{i \neq j}^{2} \frac{\left(3\left(p_{i}-G_{1}\right)+G_{3}\right) Z_{i}\left(\tau^{\prime}\right)}{p_{i}-p_{j}} \sin \frac{\pi n x}{l} \cos m \theta
\end{aligned}
$$

Here,

$$
\begin{gathered}
p_{i}=\frac{G_{1}+G_{4}}{2}+(-1)^{i} \sqrt{\frac{\left(G_{1}-G_{4}\right)^{2}}{4}+G_{2} G_{3}}, \quad G_{1}=\left(H_{1}^{(1)} \mu_{n}^{2}+H_{2}^{(1)} m^{2}\right) \delta^{2}+\mathrm{Bi} \\
G_{2}=-H_{3}^{(1)} \delta, \quad G_{3}=0, \quad G_{4}=3\left[\left(H_{1}^{(3)} \mu_{n}^{2}+H_{2}^{(3)} m^{2}\right) \delta^{2}+H_{3}^{(1)}+\mathrm{Bi}\right]
\end{gathered}
$$

$\mu_{n}=\frac{\pi n R}{l}, \mathrm{Bi}=\frac{\alpha_{z} h}{\lambda_{0}}, \tau^{\prime}=\frac{\lambda_{0} \tau}{c_{\varepsilon} h^{2}}, \delta=\frac{h}{R}, H_{j}^{(k)}=\frac{\Lambda_{j}^{(k)}}{2 h \lambda_{0}}, \lambda_{0}$ is a characteristic coefficient of thermal conductivity;

$$
Q_{m n}=\frac{k_{0}}{\pi l} \int_{0}^{l} \int_{-\pi}^{\pi} t_{c}(x, \theta) \sin \frac{\pi n}{l} x \cos m \theta d x d \theta, \quad k_{0}=\left\{\begin{array}{l}
1, m=0 \\
2, m \neq 0
\end{array}\right.
$$




$$
Z_{i}\left(\tau^{\prime}\right)=\int_{0}^{\tau^{\prime}} t(v) e^{-p_{i}\left(\tau^{\prime}-v\right)} d v, \quad(i=1,2)
$$

The system of equilibrium equations (2) under boundary conditions (4) is also solved by the method of double Fourier transform. As a result, we obtain a system of algebraic equations to determine the Fourier coefficients, and then in terms of these coefficients, we express the generalized displacements

$$
\begin{aligned}
\left\{u, \gamma_{1}\right\} & =\sum_{n=0}^{\infty} \sum_{m=0}^{\infty}\left\{U_{m n}, \Gamma_{1 m n}\right\} \cos \frac{\pi n}{l} x \cos m \theta \\
\left\{v, \gamma_{2}\right\} & =\sum_{n=1}^{\infty} \sum_{m=1}^{\infty}\left\{V_{m n}, \Gamma_{2 m n}\right\} \sin \frac{\pi n}{l} x \sin m \theta \\
\left\{w, \gamma_{3}\right\} & =\sum_{n=1}^{\infty} \sum_{m=0}^{\infty}\left\{W_{m n}, \Gamma_{3 m n}\right\} \sin \frac{\pi n}{l} x \cos m \theta
\end{aligned}
$$

According to the found generalized displacements (9) and temperature characteristics (6), we determine the components of internal forces and moments

$$
\begin{aligned}
& N_{1}=A_{11} \frac{\partial u}{\partial x}+\frac{A_{12}}{R}\left(\frac{\partial v}{\partial \theta}+w\right)+A_{13} \gamma_{3}-A_{11}^{t} T_{1}, \\
& N_{2}=A_{12} \frac{\partial u}{\partial x}+\frac{A_{22}}{R}\left(\frac{\partial v}{\partial \theta}+w\right)+A_{23} \gamma_{3}-A_{22}^{t} T_{1}, \\
& M_{1}=D_{11} \frac{\partial \gamma_{1}}{\partial x}+\frac{D_{12}}{R}\left(\frac{\partial \gamma_{2}}{\partial \theta}+\gamma_{3}\right)-\frac{D_{11}^{t}}{h} T_{2}, \\
& M_{2}=D_{12} \frac{\partial \gamma_{1}}{\partial x}+\frac{D_{22}}{R}\left(\frac{\partial \gamma_{2}}{\partial \theta}+\gamma_{3}\right)-\frac{D_{22}^{t}}{h} T_{2} .
\end{aligned}
$$

\section{Solutions for cosinusoidal variable environmental temperature, which increases to a given temperature at a finite speed}

Consider the case when the functions of the distribution of environment temperature $t_{c}(x, \theta)$ and $t(\tau)$ have the form [18]

$$
\begin{gathered}
t_{c}(x, \theta)=\frac{1}{4}\left[1-\cos \frac{\left[x-\left(x_{0}-d\right)\right]}{d}\right]\left(1+\cos \frac{\pi \theta}{\eta}\right) N(x) N(\theta), \\
t(\tau)=1-e^{-\beta \tau} .
\end{gathered}
$$

Here, $N(x)=S_{-}\left(x-\left(x_{0}-d\right)\right)-S_{+}\left(x-\left(x_{0}+d\right)\right) ; N(\theta)=S_{-}(\theta+\eta)-S_{+}(\theta-\eta) ; \beta=$ const is the parameter that characterizes the rate of temperature rise;

$$
S_{+}(x)=\left\{\begin{array}{l}
1, x>0 \\
0, x \leqslant 0
\end{array} \quad \text { and } \quad S_{-}(x)=\left\{\begin{array}{l}
1, x \geqslant 0 \\
0, x<0
\end{array}\right.\right.
$$

are unit step-functions; $2 d$ and $2 \eta$ are the width and angle of the heating area; $\left(x_{0}, 0\right)$ are the coordinates of the center of this area.

From relations (7) and (11), we obtain the following expressions for Fourier coefficients $Q_{n m}$ :

$$
Q_{n m}=\frac{2}{\pi^{2}}\left(\frac{n}{(l / d)^{2}-n^{2}}+\frac{1}{n}\right)\left(\frac{m}{(\pi / \eta)^{2}-m^{2}}+\frac{1}{m}\right) \sin \frac{\pi n d}{l} \sin \frac{\pi n x_{0}}{l} \sin m \eta,
$$

for $m \neq \pi / \eta, n \neq l / d$ 


$$
\begin{aligned}
Q_{n m} & =\frac{1}{\pi n}\left(\frac{m}{(\pi / \eta)^{2}-m^{2}}+\frac{1}{m}\right) \sin \frac{\pi x_{0}}{d} \sin m \eta, \quad \text { for } m \neq \pi / \eta, \quad n=l / d, \\
Q_{n m} & =\frac{1}{\pi m}\left(\frac{n}{(l / d)^{2}-n^{2}}+\frac{1}{n}\right) \sin \frac{\pi n d}{l} \sin \frac{\pi n x_{0}}{l}, \quad \text { for } m=\pi / \eta, \quad n \neq l / d, \\
Q_{n m} & =\frac{1}{2 n m} \sin \frac{\pi x_{0}}{d}, \quad \text { for } m=\pi / \eta, \quad n=l / d, \\
Q_{n 0} & =\frac{\eta}{\pi^{2}}\left(\frac{n}{(l / d)^{2}-n^{2}}+\frac{1}{n}\right) \sin \frac{\pi n d}{l} \sin \frac{\pi n x_{0}}{l}, \quad \text { for } n \neq l / d, \\
Q_{n 0} & =\frac{\eta}{2 \pi n} \sin \frac{\pi x_{0}}{d}, \quad \text { for } \quad n=l / d .
\end{aligned}
$$

The time function $Z_{i}\left(\tau^{\prime}\right)$ is found by formulas (8) using expression (12) in the form

$$
Z_{i}\left(\tau^{\prime}\right)=\frac{1}{p_{i}}\left(1-e^{-p_{i} \tau^{\prime}}\right)+\frac{1}{\beta-p_{i}}\left(e^{-\beta \tau^{\prime}}-e^{-p_{i} \tau^{\prime}}\right) .
$$

According to the expressions of integral characteristics $T_{1}$ and $T_{2}$ of temperature found on the basis of relations (6), (7) from relations (9), (10), we write the expressions of generalized displacements $U$, $V, W$ and components $N_{1}$ and $N_{2}$ of efforts and $M_{1}$ and $M_{2}$ moments.

\section{Numerical research}

The calculations were performed for a three-layer shell of symmetrical structure $\left(90^{\circ} / 0^{\circ} / 90^{\circ}\right)$. The material of the layers is a graphite-epoxy composite with the following physical and mechanical properties [3,14]: $\nu_{12}=\nu_{23}=0.25 ; E_{1}=172.72 \mathrm{GPa} ; E_{2}=E_{3}=6.909 \mathrm{GPa} ; G_{12}=G_{13}=3.45 \mathrm{GPa} ; G_{23}=$ $1.38 \mathrm{GPa} ; \alpha_{1}^{t}=3.34 \cdot 10^{-6} 1 / \mathrm{K} ; \alpha_{2}^{t}=\alpha_{3}^{t}=26.1 \cdot 10^{-6} 1 / \mathrm{K} ; \lambda_{1}=36.42 \mathrm{~W} / \mathrm{mK} ; \lambda_{2}=\lambda_{3}=0.96 \mathrm{~W} / \mathrm{mK}$, where index " 1 " indicates the properties of the material along the reinforcing fibers, and indices " 2,3 " indicate the properties in the perpendicular direction. The values of other parameters are as follows: $h / R=0.05 ; l / R=3 ; \eta=\pi / 4 ; d / l=(R / l) \sin \eta ; x_{0}=l / 2 ; \lambda_{0}=\lambda_{2} ; k^{\prime}=5 / 6 ; \mathrm{Bi}=0.2 ; \tau^{\prime}=10$.

Calculated the dimensionless displacements $w^{\prime}=\frac{w}{R \alpha_{1}^{t} t^{*}}, u^{\prime}=\frac{u}{R \alpha_{1}^{t} t^{*}}$, tractions $N_{i}^{\prime}=\frac{10 N_{i}}{E_{1} h \alpha_{1}^{t} t^{*}}$ and moments $M_{i}^{\prime}=\frac{M_{i}}{E_{1} h^{2} \alpha_{1}^{t} t^{*}},(i=1,2)$, for four values of the dimensionless parameter $\beta$ : $0.01,0.05,0.1$ and 10 .

Figure 1 illustrates the variation of the radial deflections $w^{\prime}$ along the guide $x^{\prime}=0.5$ and the generator $\theta=0$, respectively. The maximum values of deflection are attained at the center of the heating area. Along the guide, the deflection is oscillatory; along the generator, it is monotonous.
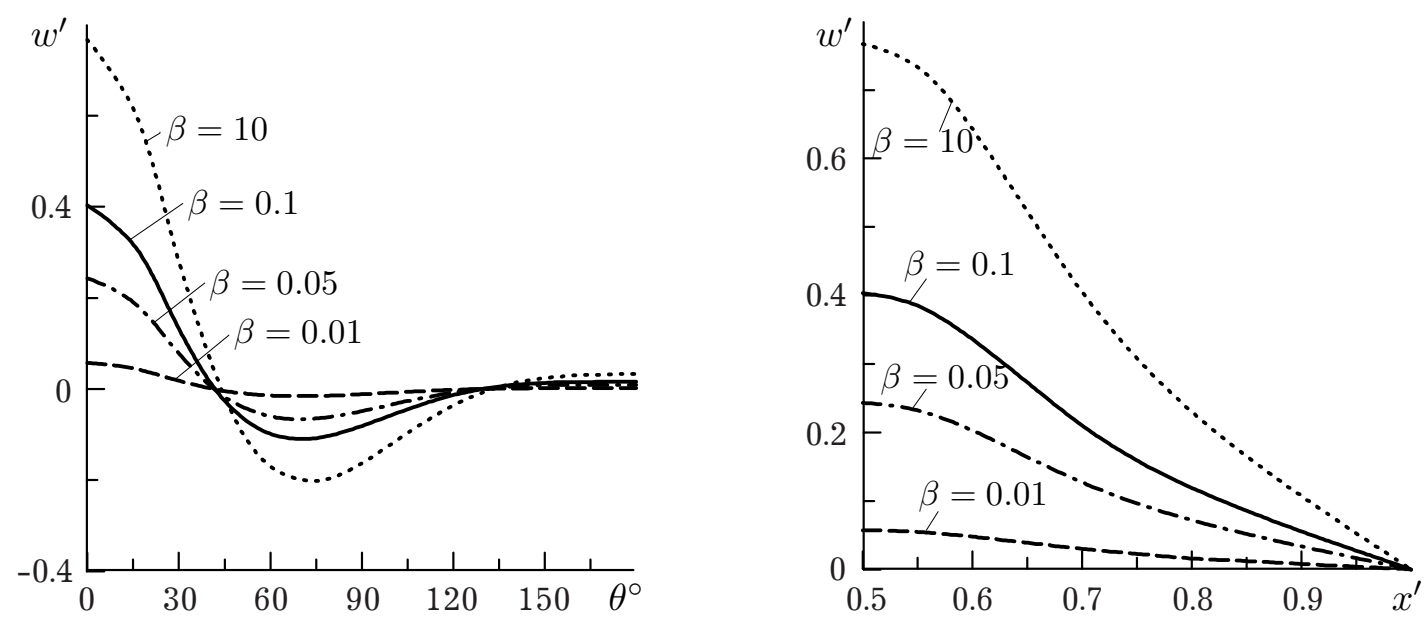

Fig. 1. The variation of the radial deflections $w^{\prime}$ along the guide $x^{\prime}=0.5$ and the generator $\theta=0$. 
The dependence of normal tractions $N_{1}^{\prime}-N_{2}^{\prime}$ on both circumferential $\theta$ and axial $x^{\prime}$ coordinates is given in Figs. 2, 3.

It is obtained that the normal fractions in the center of the heating area are always compressive. The change $N_{1}^{\prime}$ along the guide and $N_{2}^{\prime}$ along the generator has an oscillating character, and they reach the maximum positive values at the boundary of the heated and unheated areas $N_{1}^{\prime}$.
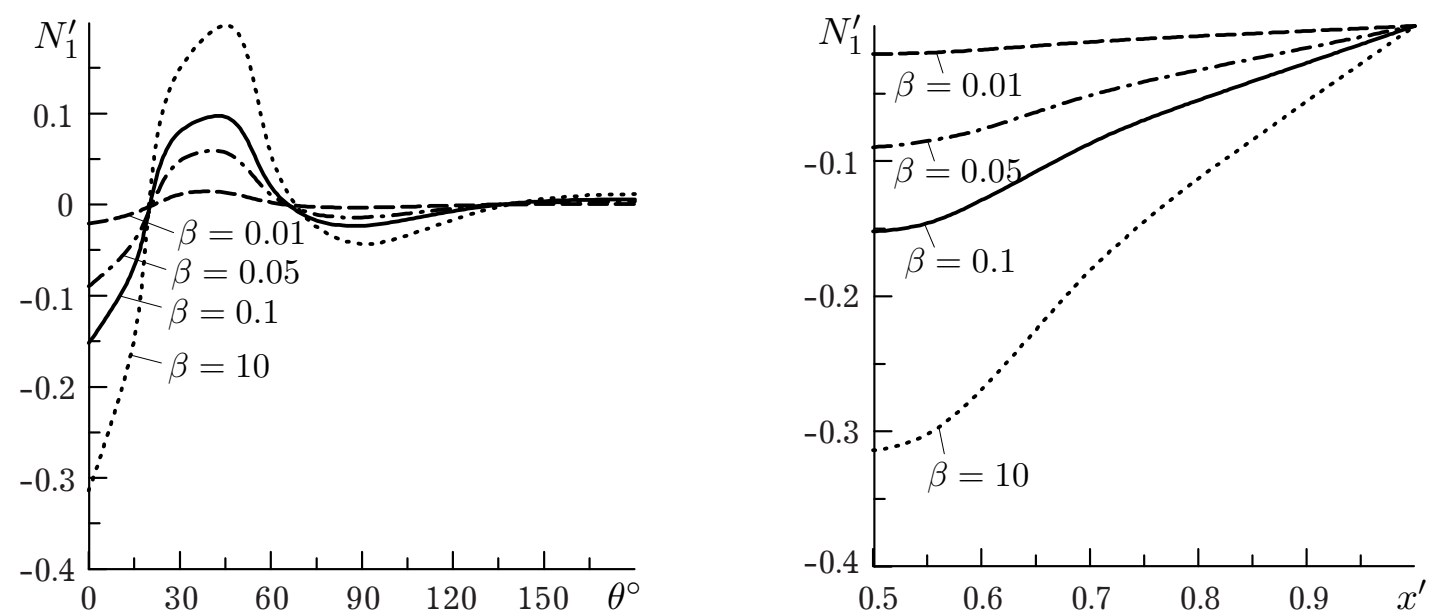

Fig. 2. The dependence of normal fractions $N_{1}^{\prime}$ on both circumferential $\theta$ and axial $x^{\prime}$ coordinates.
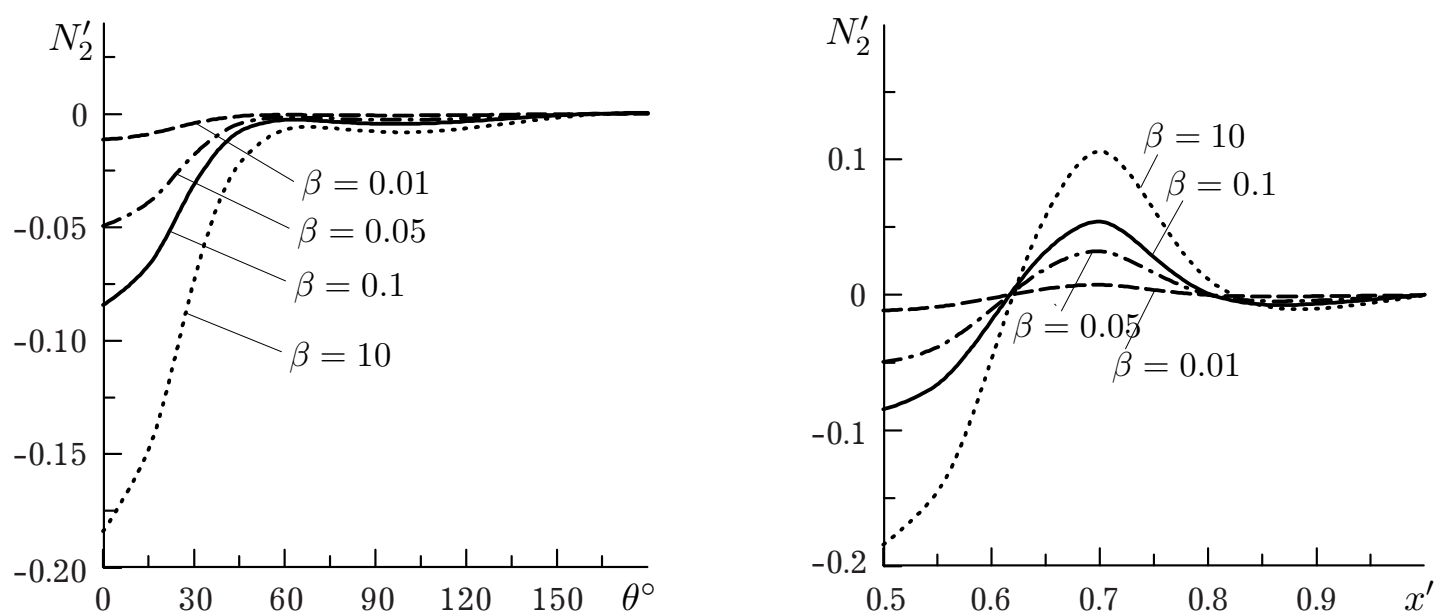

Fig. 3. The dependence of normal fractions $N_{2}^{\prime}$ on both circumferential $\theta$ and axial $x^{\prime}$ coordinates.
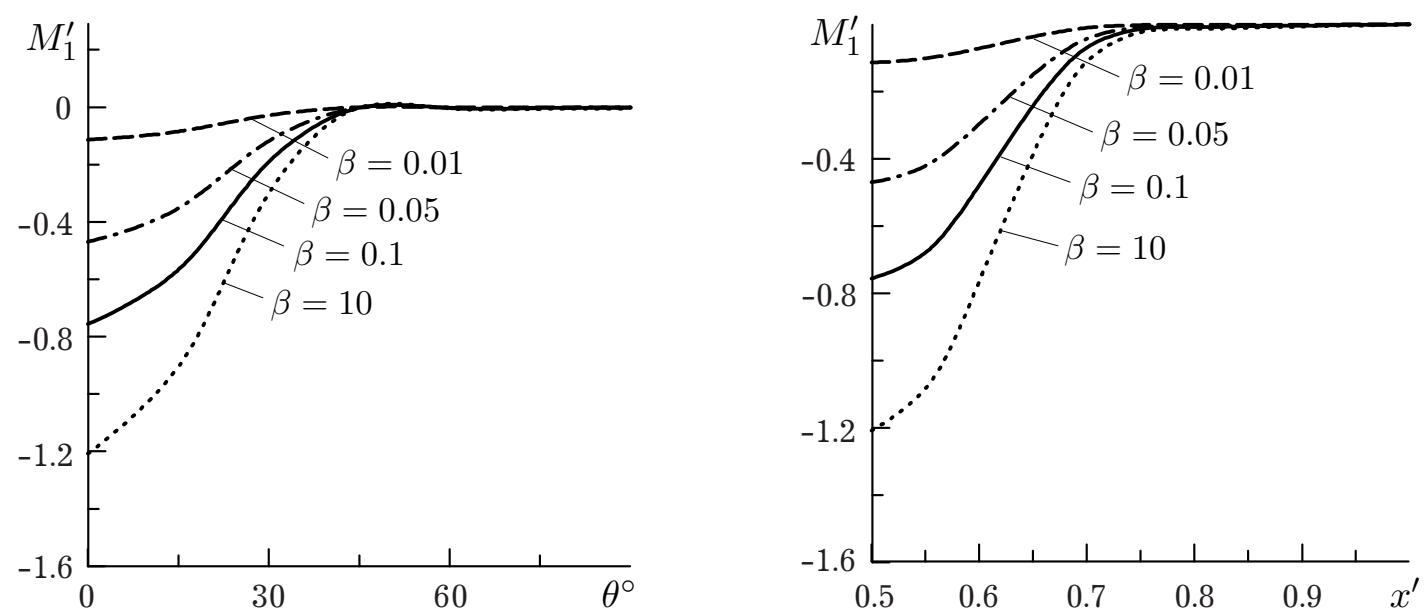

Fig. 4. The variation of bending moments $M_{1}^{\prime}$ along both the guide and the generation one, starting from the center of the heating region. 
The variation of bending moments $M_{1}^{\prime}$ and $M_{2}^{\prime}$ along both the guide and the generation one, starting from the center of the heating region, is shown in Figs. 4,5. It is obtained that the nature of their change is monotonic both in the direction of the guide and in the direction of the generator: from the maximum negative values in the center of the heating area to zero values in the unheated region. Maximum values $M_{1}^{\prime}$ are greater than $M_{2}^{\prime}$.
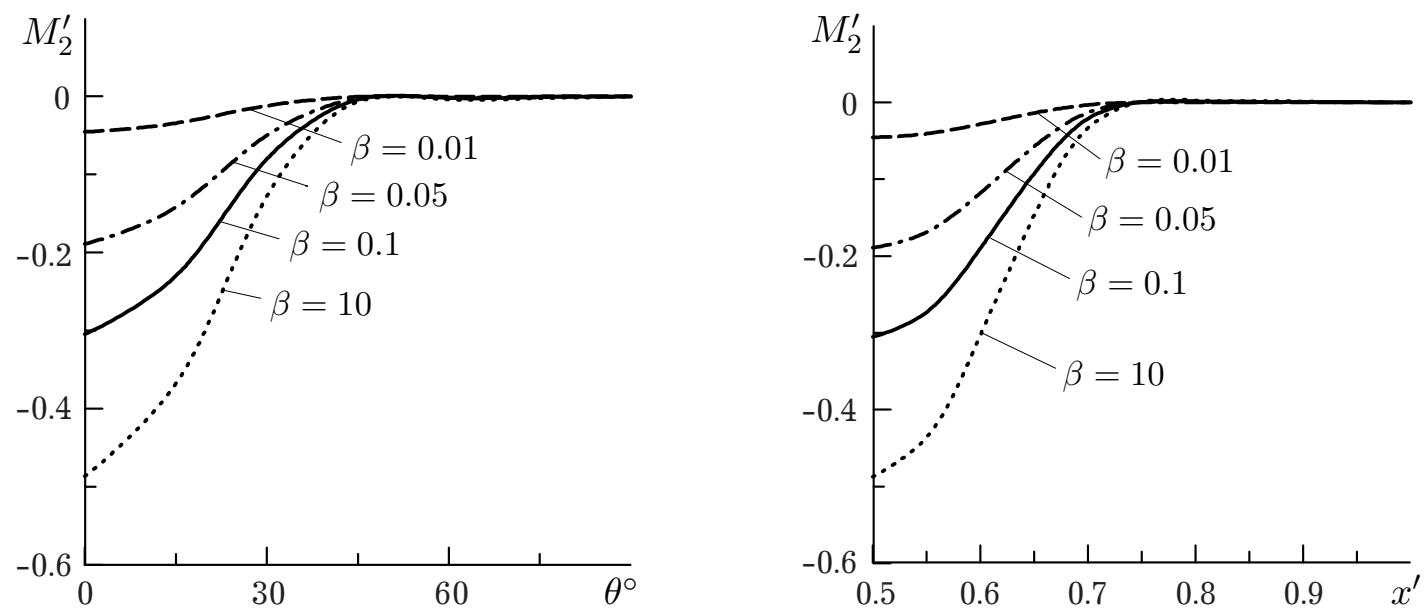

Fig. 5. The variation of bending moments $M_{2}^{\prime}$ along both the guide and the generation one, starting from the center of the heating region.
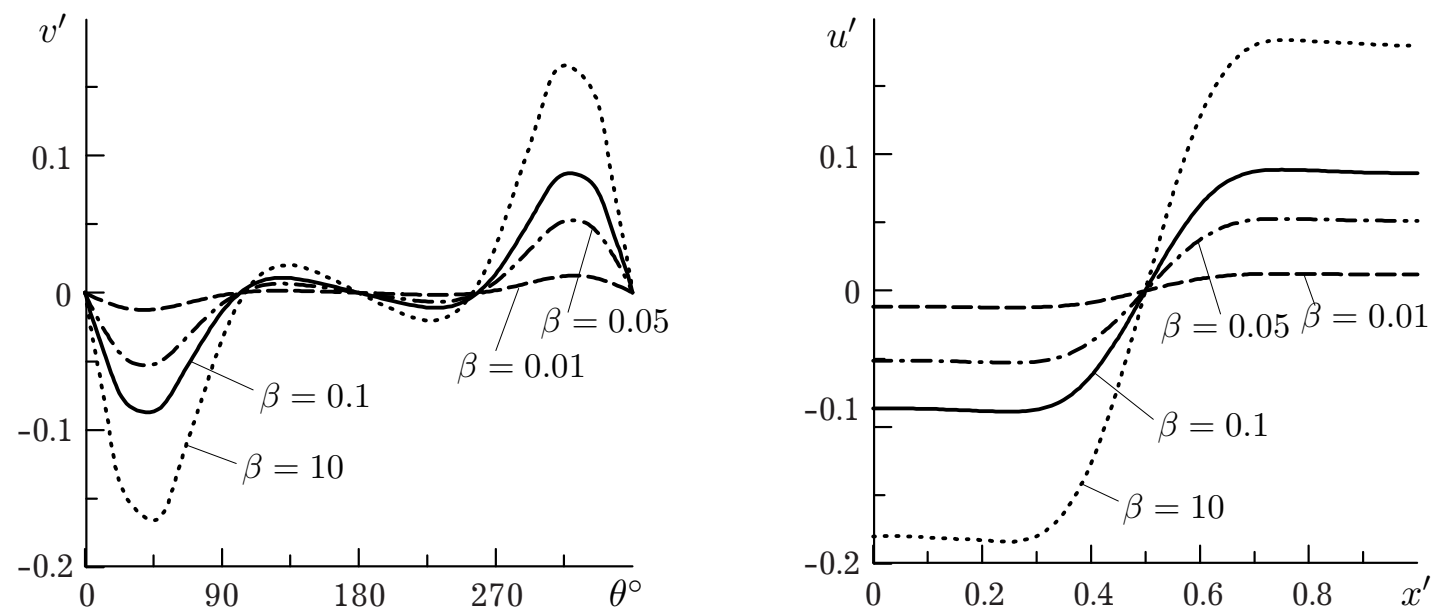

Fig. 6. The variation of the tangential displacements $v^{\prime}$ and $u^{\prime}$ along both the guide $x^{\prime}=0.5(0 \leqslant \theta \leqslant 2 \pi)$ and the generator $\theta=0\left(0 \leqslant x^{\prime} \leqslant 1\right)$.

Fig. 6 illustrates the variation of the tangential displacements $v^{\prime}$ and $u^{\prime}$ along both the guide $x^{\prime}=0.5$ $(0 \leqslant \theta \leqslant 2 \pi)$ and the generator $\theta=0\left(0 \leqslant x^{\prime} \leqslant 1\right)$. These displacements reach maximum values at the boundary of the heated and unheated areas, and in their midpoints change the sign to the opposite.

\section{Conclusions}

On the basis of the linear theory of thermoelasticity of inhomogeneous anisotropic shells with six degrees of freedom, the stress-strain state of a layered orthogonally reinforced closed cylindrical shell with a finite length, which is heated by the environment whose temperature varies exponentially and cosinusoidally. The solution of the problems of heat transfer and thermoelasticity is obtained in a closed form using integral Fourier and Laplace transforms. The dependence of radial and tangential displacements, normal forces and bending moments on axial and circular coordinates for different values of the coefficient that characterizes the effect of sudden heating are investigated. As this coefficient 
increases, the values of physical quantities determining the stress-strain state increase. It is established that the stratification of shells leads to a decrease in stresses and to an increase in displacements, which is a consequence of less effective stiffness of inhomogeneous shells.

[1] Musij R., Zhydyk U., Drohomyretska K., Kushka B., Shynder V. Modeling and Computer Analysis of Temperature of a Dental Crown Made of Isotropic Functionally Gradient Metal-Ceramics. International Conference on Perspective Technologies and Methods in MEMS Design. 94-97 (2020).

[2] Musii R. S., Zhydyk U. V., Mokryk O. Ya., Melnyk N. B. Functionally gradient isotropic cylindrical shell locally heated by heat sources. Mathematical Modeling and Computing. 6 (2), 367-373 (2019).

[3] Reddy J. N. Mechanics of laminated composite plates and shells. Theory and analysis. New York, CRC Press (2004).

[4] Hetnarski R. Encyclopedia of Thermal Stresses. Springer (2014).

[5] Kushnir R. M., Nykolyshyn M. M., Zhydyk U. V., Flyachok V. M. On the theory of inhomogeneous anisotropic shells with initial stresses. Journal of Mathematical Sciences. 186, 61-72 (2012).

[6] Gembara N., Luchko J. Modeling of thermal conductivity of shells with bilateral multilayer coating. Bulletin of TNTU. 69 (1), 222-230 (2013).

[7] Tokovyy Y., Chyzh A., Ma C. C. An analytical solution to the asymmetric thermoelasticity problem for a cylinder with arbitrarily varying thermomechanical properties. Acta Mechanica. 230, 1469-1485 (2019).

[8] Wang H. M., Ding H. J. Transient thermoelastic solution of a multilayered orthotropic hollow cylinder for axisymmetric problems. Journal of Thermal Stresses. 27 (12), 1169-1185 (2004).

[9] Zhydyk U. V. Laminated cross-ply cylindrical shell due to transient heating. Applied Problems of Mechanics and Mathematics. 17, 113-120 (2019).

[10] Fazelzadeh S. A., Rahmani S., Ghavanloo E., Marzocca P. Thermoelastic vibration of doubly-curved nanocomposite shells reinforced of doubly-curved of doubly-curved nano-composite shells reinforced. Journal of Thermal Stresses. 42 (1), 1-17 (2019).

[11] Punera D., Kant T., Desai Y. M. Thermoelastic analysis of laminated and functionally graded sandwich cylindrical shells with two refined higher order models. Journal of Thermal Stresses. 41 (1), 54-79 (2018).

[12] Ootao Y., Tanigawa Y., Miyatake K. Transient thermal stresses of cross-ply laminated cylindrical shell using a higher-order shear deformation theory. Journal of Thermal Stresses. 33 (1), 55-74 (2010).

[13] Pandey S., Pradyumna S. Transient stress analysis of sandwich plate and shell panels with functionally graded material core under thermal shock. Journal of Thermal Stresses. 41 (5), 543-567 (2018).

[14] Brischetto S., Carrera E. Coupled thermo-mechanical analysis of one-layered and multilayered isotropic and composite shells. Computer Modeling in Engineering \& Sciences. 56 (3), 249-301 (2010).

[15] Li Y., Yang L., Zhang L., Gao Y. Exact thermoelectroelastic solution of layered one-dimensional quasicrystal cylindrical shells. Journal of Thermal Stresses. 41 (10-12), 1450-1467 (2018).

[16] Matsunaga H. Thermal buckling of cross-ply laminated composite shallow shells according to a global higher-order deformation theory. Composite Structures. 81 (2), 210-221 (2007).

[17] Mirsky I. Vibrations of orthotropic thick cylindrical shells. The Journal of the Acoustical Society of America. 36 (1), 41-51 (1964).

[18] Shirakawa K., Ochiai Y. Transient response of cylindrical shells to localized heat sources. Nuclear Engineering and Design. 54 (3), 337-447 (1979). 


\title{
Напружено-деформований стан шаруватої циліндричної оболонки за локального конвективного нагрівання
}

\author{
Мусій Р. С., Жидик У. В., Турчин Я. Б., Свідрак І. Г., Байбакова I. М. \\ Начіональний університет "Львівсъка політехніка", \\ вул. С. Бандери, 12, Лъвів, 79013, Украӥна
}

\begin{abstract}
Досліджено напружено-деформований стан шаруватої композитної кругової циліндричної оболонки за локального нагрівання довкіллям через конвективний теплообмін. Для цього використано рівняння шестимодальної теорії термопружності і двовимірне рівняння теплопровідності неоднорідних анізотропних оболонок. Методами інтегральних перетворень Фур'є і Лапласа знайдено розв'язок нестаціонарної задачі теплопровідності та квазістатичної задачі термопружності для скінченної шарнірно опертої ортогонально армованої оболонки симетричної структури. Числові результати наведено для тришарової оболонки.
\end{abstract}

Ключові слова: термопружність, шаруваті матеріали, температурне навантаження, ииліндрична оболонка. 